\title{
A ENTREVISTA NA PESQUISA EM COMUNICAÇÃO: REFLEXÕES METODOLÓGICAS SOBRE DUAS EXPERIÊNCIAS PRÁTICAS
}

INTERVIEW IN COMMUNICATION RESEARCH: METHODOLOGICAL REFLEXIONS ON TWO PRACTICAL EXPERIENCES

Luis Mauro Sa Martino', Alessandra Goulart Lopes², Vanessa Rodrigues Puerta Souza

RECEBIDO: 28/06/2019 |ACEITO: 02/09/2019

DOI: $10.5902 / 2317175838788$

\section{RESUMO}

Este artigo discute os aspectos metodológicos de duas experiências de pesquisa que utilizaram, como técnica de obtenção de dados, a entrevista em profundidade. A partir da análise dessas situações de entrevista, confrontado com pesquisa bibliográfica, destacam-se três aspectos dessa prática metodológica relacionados à tomada de decisão no momento de realização das entrevistas, entendidos como (1) a escolha dos entrevistados e as condições iniciais da entrevista; (2) o momento da entrevista como encontro intersubjetivo e (3) o problema da validade dos dados obtidos nesse tipo de interação. Esses elementos são discutidos contra o pano de fundo de outras questões epistemológicas ligadas à pesquisa em Comunicação.

PALAVRAS-CHAVE: Entrevista. Metodologia Qualitativa. Pesquisa em Comunicação.

\footnotetext{
1 Jornalista e Professor na graduação e pós-graduação em Comunicação na Contemporaneidade da Faculdade Cásper Líbero. Doutor em Ciências Sociais pela PUC-SP. Foi pesquisador-bolsista na Universidade de East Anglia, Inglaterra. Autor dos livros "Teoria da Comunicação" (Vozes, 2009) e "Comunicação \& Identidade" (Paulus, 2010), entre outros.

2 Mestranda em Comunicação pela Faculdade Cásper Líbero.

3 Mestra em Comunicação pela Faculdade Cásper Líbero
} 


\section{ABSTRACT}

This paper addresses some methodological issues concerning the use of qualitative interviews in Communication Research, focusing on two projects related to researches. It discusses some aspects of the decision-making in the interview process by arguing that, far from being a technique, qualitative interview might be seen as part of a broader communication process that includes, but is not limited to, three main elements: (1) the interviewees' choice and the initial conditions of the interview; (2) the moment of the interview as an intersubjective encounter and (3) the problem of the validity of the data obtained in this type of interaction. These elements are discussed against the backdrop of other epistemological issues linked to Communication research.

KEYWORDS: Qualitative Interview. Methodology. Communication Research.

\section{Introdução}

Em 1937, o sociólogo Paul Lazarsfeld indicava em seus trabalhos as vantagens do uso de entrevista para obtenção de dados a respeito das tendências e do efeitos dos meios de comunicação em determinados grupos sociais. Esse parece ser um dos primeiros, se não o primeiro, registro da utilização de técnicas de entrevista na então nascente pesquisa em Comunicação. Cerca de oitenta anos depois, Arsel (2017) continuava indicando a presença majoritária de entrevistas como método de pesquisa nos estudos de comunicação e público. Essa longevidade permite também questionar, em termos metodológicos, a pertinência de procedimentos de entrevista na pesquisa em Ciências Sociais - no caso, a Comunicação.

Este texto nasce de um problema prático referente à utilização de entrevistas na pesquisa qualitativa, a partir das experiências e vivências na elaboração de duas dissertações de Mestrado. Os questionamentos compartilhados aqui nascem dos diálogos de orientação, das reuniões de grupos de pesquisa e de conversas menos formais, mas igualmente sintomáticas das dificuldades e possibilidades da entrevista. Trata-se de um exercício de reflexividade epistemológica com vistas a "desnaturalizar" o processo de entrevistas na prática de pesquisa e objetivar momentos menos discutidos das interações entre sujeito -pesquisador e sujeito-pesquisado, procurando, em certa proporção, inverter a relação do visível e do invisível na utilização de entrevistas na pesquisa como recorda Bourdieu (1983, p. 180), não se entra na "cozinha das ciências". De acordo com Lucrécia Ferrara (1996), o método se desenrola no confronto com a dinâmica do objeto de pesquisa a partir de indagaç̃es, em uma abertura e reabertura constante das perspectivas de pesquisa diante da realidade. Assim, a entrevista não é uma "técnica" a ser "aplicada", mas deriva do encontro entre interrogações iniciais da pesquisa e o campo que se apresenta para a obtenção de respostas, geradoras, por sua vez, de novas perguntas.

A opção por trazer a reflexão a partir de duas pesquisas sobre Comunicação, Souza (2019) e Lopes (2019), uma concluída e outra em fase de conclusão, que utilizaram entrevistas para sua elaboração, está ligada a uma demanda de compreender a entrevista como um momento privilegiado de encontro entre subjetividades, no qual a escuta se apresenta como peça fundamental, e do qual emergem sentidos além dos esperados em qualquer roteiro ou projeto. O texto não se propõe a discutir o "como se faz" a entrevista, mas pensar o método em sua dinâmica, a entrevista como movimento, como gesto da pesquisadora ou pesquisador na direção de uma alteridade e, por isso, espaço de uma visada ética, que, ultrapassando o domínio da "ética na pesquisa", se apresenta como ética do encontro com a alteridade na comunicação, indicam Martino e Marques (2018). Estados da arte sobre entrevistas podem ser encontrados em Manzini (2012), Jensen e Christy (2013) e, sobre Comunicação, Mariano (2018).

Vale situar brevemente cada um dos estudos a partir dos quais esta reflexão metodológica se origina. Umas das pesquisas analisou a comunicação entre professores e alunos, observada nas dimensões da violência, em instituições de educação pública, do $6^{\circ}$ ano do ensino fundamental ao $3^{\circ}$ ano do ensino médio. Foram realizadas 11 entrevistas com professoras e professores. A outra estudou a comunicação entre funcionários de multinacionais. Foram entrevistados cinco brasileiros que trabalham no exterior e cinco estrangeiros que trabalham no Brasil, em cargos de gestão, para delinear como suas identidades, entrelaçadas com sua (s) cultura (s) nacional (is), articulam-se com os modos de trabalho das corporações, em um cenário permeado por tensões entre códigos culturais.

Apesar das diferenças consideráveis entre os dois cenários, as entrevistas se mostraram particularmente frutíferas para o estabelecimento de relações comunicacionais com a alteridade. Além de "obter dados", a entrevista em si apresentou-se como um momento de comunicação, no qual havia necessidade de uma exploração metodológica mais detalhada. Quais potências da entrevista permitem essa elaboração da experiência no encontro intersubjetivo entre entrevistador e entrevistado? Essa pergunta, nascida a partir da prática da pesquisa, é endereçada neste texto. Para delinear alguns aspectos dessa questão, coloca-se em perspectiva as possibilidades e limites da comunicação com a alteridade, e as estratégias de entrevistadas e entrevistados para lidar com esses desafios. Se, como afirma Braga (2013), todo processo de pesquisa é um conjunto de "tomadas de decisão", este texto se dedica a observar, em maior detalhe, três desses momentos, conforme elas se desenrolaram nos diálogos de orientação: (1) a escolha dos entrevistados e do local; (2) o momento do encontro inicial e (3) o conhecimento possível que emerge dessa relação.

\section{2 "Sim, aceito falar com você": a aproximação inicial com os} entrevistados

Um ponto inicial é a busca por entrevistados a partir do recorte delimitado no objetivo de cada pesquisa. Esta fase demanda planejamento de tempo para o contato inicial com potenciais entrevistados, em uma constante negociação, para, no ritmo acelerado das sociedades contemporâneas, encontrar brechas em seu tempo para a entrevista. 
O procedimento seguiu com a escolha de indivíduos que tenham experiências relacionada com o tema da pesquisa. Um dos quesitos de seleção foi a trajetória profissional dos potenciais entrevistados. Outro aspecto, relacionado ao estudo de Potter (2018), ligou-se a acessibilidade às fontes, relacionada ao trânsito que o pesquisador tem para conseguir contatar os potenciais entrevistados. Seriam pessoas do mesmo círculo social, dependeriam de intermediários para contatar, ou estariam fora de contato? Mais ainda, qual é o número de pessoas a entrevistar? Na pesquisa sobre educação, pela facilidade de acesso foram escolhidas instituições do município de Diadema e da Zona Sul de São Paulo. O ponto de partida foi enxergar o processo de comunicação nas vivência dos entrevistados, procurando compreender suas relações com o ambiente de trabalho. $O$ critério para encontrar os professores foi a indicação entre os próprios entrevistados, foi acionada uma rede de contato com educadores.

Em relação a quantidade de entrevistados, a decisão de parar pode ocorrer, segundo a literatura, quando os elementos estudados passam a se repetir sistematicamente. Fraser e Gondim (2004, p. 147) abordam que "em um ambiente social específico, o espectro de opiniões é limitado, pois a partir de um determinado número de entrevistas percebe-se o esgotamento das respostas quando elas tendem a se repetir e novas entrevistas não oferecem ganho qualitativo", uma vez que, diferentemente do método quantitativo, na análise qualitativa não serão contadas repetições de termos ou palavras, indica Santaella (2001). No caso das multinacionais, foram selecionados gerentes e diretores de empresas globais em situação de expatriação, responsáveis por gerenciar equipes com membros de diversas nacionalidades. Comunicam-se majoritariamente em inglês, embora não seja a língua materna de quase nenhum deles. Observou-se que os estrangeiros no Brasil apresentavam visão similar sobre a comunicação intercultural, assim como as características apontadas pelos gestores brasileiros no exterior, confirmando, assim, a abordagem de Santaella (2001).

Um dos pontos que pareceram facilitar o contato foi a percepção, por parte dos entrevistados, do domínio do entrevistador sobre o tema, assim como das contribuições da pesquisa para sua área de atuação, especialmente quando o problema é conhecido em seu ambiente de trabalho. A existência de um terreno prévio comum parece ter sido determinante para essa conquista de legitimidade perante futuros entrevistados.

O aceite do entrevistado se apresenta como o início de uma série de expectativas em relação ao que poderá ser obtido na entrevista. É preciso levar em consideração que uma pessoa está cedendo seu tempo para contribuir com a pesquisa e, de alguma maneira, também formula expectativas a respeito do resultados. Foi necessário o tempo todo adequar seu roteiro semiestruturado ao tempo disponível para a entrevista. "A percepção e experiência de tempo está entre um dos aspectos centrais do funcionamento de um grupo" (SCHEIN 2004 , p. 151). No caso do agendamento com os brasileiros que moram no exterior, foi necessária flexibilidade da pesquisadora devido aos variados fusos horários, visto que os profissionais moravam, na época da pesquisa, na França, Alemanha, Coreia do Sul e Estados Unidos, sendo um na costa oeste e a outra na capital norte-americana. Houve dois cancelamentos: uma residente na Nova Zelândia que não podia falar durante o expediente e tem filho pequeno, e outro que estava de mudança do Japão para os Estados Unidos.

Apesar das propostas e recomendaç̃es de manuais de metodologia, nesse momento, há algo quase "intuitivo": o entrevistador, a partir das práticas anteriores, "sente", no sentido do cálculo não racionalizado, vinculado à formação de seu habitus profissional (BOURDIEU, 2005; BARROS FILHO; MARTINO, 2003; ARSEL, 2017), o momento de interromper e retomar o roteiro ou manter os novos temas. Partindo destas considerações, de que não existe um procedimento padrão a ser seguido, foi necessário um exercício crítico de observação e revisão constante, como indicam Bauer e Gaskell (2008, p. 27), "os pesquisadores qualitativos encontram pouca clareza e orientação na literatura para seus procedimentos" (BAUER; GASKELL, 2008, p. 27).

Essa relação é estabelecida a partir de um laço mútuo de confiança e reconhecimento recíproco de seus respectivos domínios de informação, direcionado para a compreensão de ambos de que o objetivo da pesquisa se associa aos seus próprios incômodos, de modo a sentir que está contribuindo para um estudo que poderá trazer respostas para suas próprias indagações e inquietudes. No caso da entrevista em multinacionais, que surgiu de tensões sentidas pela pesquisadora durante sua trajetória corporativa, houve franca abertura empática, a partir de espaços que foram criados pela identificação e pelos aspectos comuns e permitiram uma aproximação, facilitando adentrar no universo simbólico do entrevistado (MARTINO, 2019).

Existe, já na escolha do entrevistado e nos contatos iniciais, a perspectiva de um processo de vinculação recíproco em uma interação comunicacional na qual fala e escuta não apenas se alternam, mas se complementam. Nas duas pesquisas os entrevistados cumpriram pontualmente a agenda de entrevistas. No caso dos professores, todos os indicados foram entrevistados e o comprometimento deles corroborou com o processo e organização das entrevistas. Do mesmo modo, os gerentes de multinacionais engajaram-se, bloqueando suas agendas de interrupções operacionais dos escritórios, dedicando seu tempo para a entrevista.

Outro ponto de preocupação, levantado por D'Éspíndula e França (2016, p. 500), é o local da entrevista, que "deve sempre oferecer ao entrevistado algum conforto e total privacidade, para que se sinta à vontade para participar e colaborar". Os detalhes de cada situação podem interferir na relação de comunicação que se coloca como centro da entrevista. Como recorda Braga (2011), o processo de comunicação se dá em relação ao conjunto de elementos de uma situação, envolvendo não apenas a fala, mas também os gestos, os protocolos esperados de cada tipo de interação, as condições do lugar e outros elementos que, embora possam parecer "menores", não deixam de inter- 
ferir no processo comunicacional, constituindo um "dispositivo interacional", expressão formulada em diálogo com Foucault. A atenção aos detalhes do ambiente enriqueceu o momento da pesquisa e auxiliou em alguns questionamentos que podem se desenvolver para aspectos não planejados inicialmente, relacionados ao ambiente, como demonstrar certo conforto e desenvoltura para dialogar nos locais ruidosos que foram escolhidos pelos professores para realizar as entrevistas.

Na pesquisa sobre educação, os professores pareciam estar à vontade demonstrando familiaridade com os lugares, por exemplo, em uma lanchonete Habib's no bairro do Jabaquara, Zona Sul de São Paulo, uma entrevistada indicou a entrada árabe que é "uma delícia" e custa $R \$ 6,90$. Isso também aconteceu nas entrevistas na área de alimentação do shopping Praça da Moça e na praça de alimentação do Carrefour, ambos em Diadema, no Rei do Mate no Shopping Eldorado, em São Paulo, no café com leite da padaria Piriquito, na Vila Santa Catarina, zona sul paulistana e em uma lanchonete do Instituto Moreira Salles na Avenida Paulista, local situado em um bairro mais elitizado da capital paulista. Outro detalhe: na hora da conta, todas e todos os professores fizeram questão de pagar o que consumiram.

No estudo sobre empresas, os entrevistados que moram no exterior sentiram-se confortáveis para falar ao telefone ou via Skype, por utilizarem este canais para se comunicar frequentemente. Mesmo os gestores que moram em São Paulo optaram por este meio, para facilitar sua logística. Um deles, fez a entrevista do táxi, aproveitando que faria uma pequena viagem para um município vizinho a São Paulo. Apenas duas entrevistas foram feitas em local público, uma em um restaurante em Campinas e outra em restaurante do Shopping Vila Olímpia.

Válido ressaltar que o "lugar" da entrevista nem sempre significa que os interlocutores estejam no mesmo espaço físico. Com as dificuldades de deslocamentos, agendas e o pouco tempo disponível para atividades além de suas rotinas, é possível utilizar a tecnologia e realizar as entrevistas por vídeo conferência ou telefone. As vantagens da proximidade virtual são contrabalançadas por eventuais perdas, por exemplo, da presença física do outro e sua linguagem corporal, importantes no caso da pesquisa empírica, na qual além do conhecimento discursivo, que é obtido pela dedução e indução, existe também aquele que "obtido por meio da observação e experimentação que se fundam na percepção sensorial" (SANTAELLA, 2001, p. 105). Também Gof fman $(2014$, p. 96) menciona que as pessoas tendem a se relacionar por "liames de dependência recíproca e recíproca familiaridade".

Por outro lado, como ressalta Menezes (2008), existem riscos de problemas de comunicação tanto na comunicação direta entre os corpos, quanto na mediada por aparatos eletrônicos. A partir da visão de Fraser e Gondim (2004 p. 140), é possível observar que a questão do espaço na entrevista está ligada à "relação intersubjetiva do entrevistador com o entrevistado, e, por meio das trocas verbais e não-verbais que se estabelecem neste contexto de interação" o que, para ambos, pode "permitir uma melhor compreensão dos significados, dos valores e das opiniões dos atores sociais a respeito de situações e vivências pessoais". Novamente, o habitus de quem pesquisa, traduzido em termos de sensibilidade e flexibilidade, foram importantes no processo de escolha do lugar, seja físico ou virtual. Trata-se de abdicar de sua zona de conforto e optar pelo local mais conveniente para o entrevistado.

\section{0 momento do encontro: o estranhamento e a identificação}

Com as entrevistas agendadas, o próximo passo é executá-las, tendo em mãos o roteiro. Com os fatores combinados de maneira confortável, será criado o espaço dialógico, quando os interlocutores conseguirem interagir, procurando contornar diferenças e barreiras e estabelecendo um espaço de relação comum. Kirk e Miller (1986, p. 21) argumentam que a problemática sujeito-objeto na pesquisa qualitativa, longe de ter sido resolvida ou corretamente analisada, ainda precisa ser endereçada no sentido de, na prática de pesquisa, encontrar dados com um mínimo de "confiança e validade", sem os quais qualquer estudo corre o risco de se tornar um relato desprovido de capacidade crítica e analítica.

Para tanto, a primeira etapa do roteiro da entrevista foi o "aquecimento", onde a intenção era conhecer um pouco o histórico do entrevistado. O aquecimento da pesquisa sobre educação foi com a intenção de conhecer um pouco da trajetória do professor, além de empatia, esse foi um momento nostálgico onde o entrevistado revisitou os primeiros momentos da carreira e possibilitou entender como escolheu ou foi escolhido pela profissão, com o propósito de "quebrar o gelo" como indicam Tedesco, Sade e Caliman (2013). Szymansky (2011) acredita que esse exercício proporciona uma aproximação e o mapeamento histórico biográfico do entrevistado, contextualizando a relação do entrevistado com o tema de pesquisa. Na outra pesquisa, a primeira pergunta foi sobre a trajetória profissional e pessoal do gestor, o que o levou à expatriação, quanto tempo se encontra no país, barreiras culturais e comunicacionais que enfrentou, para somente após este relato, interligar com as demais perguntas. Essa conexão inicial fez emergir sentimentos e lembranças que permaneceram ao longo das entrevistas.

Este primeiro momento foi pensado no sentido de auxiliar os interlocutores a transporem a barreira do estranhamento. Rizo e Romeu (2006, p. 13) conceituam como "fronteira" o limite mental ou imaginário, além do real ou físico, baseado no ordenamento submetido às dimensões da vida, como o tempo e o espaço, os comportamentos e as ações, os desejos, as aspirações e frustrações. Para compreender essas fronteiras, segundo as autoras, é necessário entender como se constroem as relações de negociação e a concorrência do "nós" e "outros". 
Isso implica a formação de uma relação de confiança desde o momento inicial do encontro, quando cada pesquisadora expôs novamente o tema e problema a serem trabalhados. Por sua vez, entrevistadas e entrevistados, ao relatarem suas trajetórias pessoais e profissionais, demonstrava novamente aderência ao trabalho. De acordo com Szymansky (2011), para o entrevistado, essa pode ser uma oportunidade para falar e ser ouvido, após a qual surge a "questão geradora" da pesquisa. Kaufmann (1996, p. 61) detecta, nos manuais e livros-textos sobre metodologia, uma tendência à perspectiva de "naturalizar" a entrevista, procurando transformá-la em uma "conversa", como se fosse possivel contornar uma situação artificial: a entrevista interrompe a rotina do entrevistado, convidado a uma reflexão diante das perguntas de quem entrevista. Para Kaufmann (1996, p. 67-72), a entrevista é uma situação de influência mútua, na medida em que a presença do outro implica uma tomada de posição: o entrevistado não está respondendo "para ninguém" ou "a partir de lugar nenhum", mas em uma situação muito bem delimitada, diante de uma pessoa que, mesmo sendo familiar, apresenta-se não como alguém de trato pessoal, mas investido de uma posição de reconhecimento - 0 "pesquisador", o "entrevistador". E evoca, como riscos de uma tentativa de desnaturalização da pesquisa, três problemas: os jogos mútuos de influência entre entrevistador e entrevistado, a fabulação das situações perguntadas os "efeitos de verdade" provocados pelo entrevistado para provocar algum impacto no entrevistador.

Em sua versão mais simples, o entrevistado diz aquilo que, em seu julgamento, o entrevistador já espera dele no sentido de dar uma resposta "correta" - não é outra a crítica de Bourdieu (1983) às pesquisas de opinião, sondagens e enquetes a respeito de algum assunto: há, sob qualquer uma delas, um jogo de pressuposições e expectativas de parte a parte que, tanto revela quanto produz informações a respeito de um assunto. No caso da pesquisa sobre empresas, como todos os gestores receberam por e-mail ou mensagem privada de redes sociais digitais os objetivos da pesquisa e pontos principais que seriam abordados, tiveram tempo para preparar algumas respostas e listar algumas das situações. Contudo, no decorrer da entrevista, outras questões surgiram e foram respondidas de forma mais improvisada, demonstrando a espontaneidade do pesquisado.

$O$ processo de engajamento inicia-se pelo pesquisador que faz o enunciado com uma expressão no olhar ou tom de voz e recebe a abertura do entrevistado, que retorna um sinal, seja com o olhar ou postura, indicando que está à disposição do outro, para a atividade proposta (GOFFMAN, 2010). Apesar dos olhos proporcionarem uma reciprocidade direta e pura, reduzindo o mundo a uma imagem bidimensional, o ouvir nos proporciona a percepção da tridimensionalidade do espaço (MENEZES, 2008). Baitello $(2005$, p. 108) sinaliza a necessidade de uma nova cultura do ouvir e de uma outra temporalidade, assim como "um novo desenvolvimento da percepção humana para as relações mais profundas, para os nexos profundos, para os sentidos e o sentir". Nas palavras de Tedesco, Sade e Caliman, o ato de ouvir vai além da informação:

\section{A escuta dos signos da experiência permite ao entrevistador acompanhar a temporalidade da entrevista. Se o entrevistador da experiência, que lhe constitui efetivamente e que lhe carac- teriza de forma singular apreendendo ferente, como um sentido pré-estabelecido. Essa separação ou binarização entre os planos do conteúdo e da expressão é que nos coloca à sscuta somente de informações. (TADESCO: SADE; CALIMAN, 2013, p. 306)}

Neste momento, no qual crescem os vínculos simbólicos e materiais, os corpos, juntamente com os sentidos, permitirão a apropriação e compartilhamento do espaço e do tempo de vida, ao passo que complexifica a comunicação (MENEZES, 2008). Estes vínculos são construídos quando existe sinergia entre pesquisador e entrevistado, o primeiro que está conduzindo o processo desde o início até o momento da entrevista com seriedade e o segundo, que está disposto a colaborar com a pesquisa. Por estarem "falando a mesma língua", ao compartilharem signos, símbolos e interpretaç̃̃es, emerge um espaço de intersubjetividade entre os interlocutores, conferindo significado aos relatos (MARTINO; MARQUES, 2017).

Em uma das entrevistas, mesmo após ter explicado os objetivos do estudo sobre educação e apresentado o termo de consentimento e livre esclarecimento, deixando claro que a entrevista possui finalidade de pesquisa acadêmica e que nesse caso será preservado o anonimato dos participantes, assegurando a privacidade, uma das professoras, que tinha acabado de passar por período de licença médica, questionou-se se poderia conceder a entrevista. Como a participante encontrava-se ainda muito sensibilizada, foi necessário parar a entrevista algumas vezes, para oferecer uma xícara de chá, tranquilizando-a e deixando-a à vontade para prosseguir ou não. Neste caso a professora se emocionava e acabava chorando ao relatar acontecimentos mais delicados, envolvendo violência verbal e física.

A sensibilidade do pesquisador em admitir que seu interlocutor - muito mais do que um "objeto de pesquisa" - é um "sujeito pesquisado" que, ao se despir da máscara que o protege e entregar-se às confidências da entrevista, traz para o encontro os desabafos de situações incomuns ou, por vezes, íntimas. Tais confidências normalmente não ocorreram no início da entrevista, mas ao longo do processo, quando o entrevistado se envolveu com o trauma de suas lembranças. Inevitavelmente, transparecem sentimentos e emoções, que são reviradas pelas memórias e conduzidas por este silencioso pedido de ajuda, que pode ser apenas por ter alguém para ouvir suas histórias. Na pesquisa sobre as multinacionais, os sentimentos emergiram mais nas mulheres entrevistadas, coincidentemente, todas brasileiras residentes no exterior, que 
relataram a dificuldade em se relacionar com os locais, devido às barreiras culturais, modos de se comportar, de rir, de cumprimentar e se aproximar. Os homens relataram mais situações engraçadas ou de conflitos e discussões mais organizacionais nas empresas.

Um exemplo, foi uma brasileira, gerente de projetos de uma multinacional de tecnologia e residente no exterior, que afirmou que, quando fo contratada, tinha uma equipe de pessoas de diversas nacionalidades e todos falavam em inglês. Depois que este primeiro projeto se encerrou, ela entrou em outro, que estava no período da entrevista, no qual todos eram do país, exceto ela. Ela contou que mesmo estudando o idioma do lugar, sendo casada com um nativo e estando lá há dois anos, ainda não era fluente e que, apesar de conseguir conduzir o projeto, não participava das outras conversas, porque os participantes comunicavam-se apenas em seu idioma nativo. Neste caso observa-se que, mesmo sendo uma gestora, por ser estrangeira e não ter fluência no idioma local, existe certo grau de exclusão da entrevistada, devido à barreira linguística. Diante de temas delicados, e a serem tratados com igua delicadeza, foi necessário fazer algumas perguntas para entender a situação sendo importante que o entrevistador não tenha feito interrupções durante a fala do entrevistado, deixando evidente sua compreensão do possível mal -estar causado, garantindo acolhimento, respeito e condições de conforto e privacidade, recordam D'Espínula e França (2016).

No estudo das multinacionais, como a maioria foi feita via vídeo conferência ou telefone, o horário de início e fim já estavam pré-estabelecidos, não havendo esse sentimento de esfriamento, principalmente com os entrevistados estrangeiros, que possuem comunicação mais direta, apesar da abertura empática e toda a atenção, educação e envolvimento com a entrevista. Já na pesquisa sobre educação o tom das entrevistas foi mais emotivo, e o roteiro foi montado em três blocos: aquecimento, pergunta desencadeadora que alicerçou os objetivos da pesquisa e por fim foi proposta uma questão de reflexão, onde cada participante tentou condensar a vivência relatada, sintetizando-a em uma palavra provocando um prolongamento do encontro após a entrevista formal com fechamento mais reflexivo, onde de maneira natural, surgiram relatos ainda mais espontâneos, capaz verbalizar e captar a singularidade de um foco.

\section{A entrevista e a ética da alteridade}

No sentido usual do termo, a noção de entrevista é entendida como maneira de "obter informaç̃̃es" a partir de perguntas por meio das quais a pessoa deve elaborar uma narrativa vinculada a um discurso sobre a realidade. Haveria, assim, uma espécie de trânsito de informações a respeito de algo que, efetivamente, "passaria" do entrevistado para o entrevistador. De posse desses dados, o pesquisador poderia utilizá-los como matéria-prima para elaboração de suas reflexões e intepretações a respeito da realidade comu- nicada pelo entrevistado. Essa perspectiva parece implicar um duplo risco: de um lado, a naturalização da situação de entrevista, como se a passagem de informações fosse, de certa maneira, direta; por outro lado, toma a comunicação como um jogo restrito à passagem imediata de informaç̃̃es entre polos distintos, a entrevistadora ou entrevistador de um lado, a pessoa entrevistada, de outro. Parece existir, subjacente a essa perspectiva, uma noção de comunicação como "transmissão", seguindo a diferença proposta por Williams (2003[1978]) e Lima (1983): há um saber no entrevistado a ser transmitido à pesquisadora ou pesquisador, que, por sua vez, vai utilizá-lo em uma pesquisa.

No entanto, partindo de uma perspectiva relacionada à origem da palavra "entrevista", é possível talvez modificar um pouco esse foco de atenção. Vale a pena, nesse sentido, destacar o "entre", vendo a entrevista é um espaço de "produção conjunta" de uma perspectiva de verdade, para seguir parcialmente o que afirmam Arsand e Arsand (2014) sobre a elaboração de "confissões" ou revelações durante a entrevista. Os componentes subjetivos e intersubjetivos do processo parecem emergir com mais força neste momento.

Apesar do processo da pesquisa ser em sua essência solitário, nos momentos de leitura e produção, há também a alteridade na pesquisa de campo. $\mathrm{Na}$ entrevista, isso se traduziu em termos de preocupação e cuidado com o entrevistado, mas também pensando na alteridade futura de leitoras e leitores. Nesse ponto, a subjetividade de quem pesquisa se entrelaça com as práticas sociais do saber, com o material empírico e teórico estudado no "espaço do nós", provocando um novo lugar de encontro, relembra Martino (2018).

O ponto de encontro com o afeto pela pesquisa acaba sendo combustível para o desenvolvimento da pesquisadora ou pesquisador, desafiando a dialogar e contextualizar o material teórico com o objeto, conscientizando - o que em ciências humanas a pesquisa está sempre próxima de um espaço subjetivo, por isso a importância de mostrar os caminhos metodológicos para delinear a pesquisa, atendendo as perguntas durante o percurso. Autoras e autores como José Luiz Braga (2010), Ciro Marcondes Filho (2012) e Lucrécia Ferrara (2012; 2013) vem trabalhando uma perspectiva comunicacional que, deixando de lado a ideia de "transmissão", parecem se orientar em termos de pensar - dentro de suas diferenças - a comunicação como uma radical tentativa de abertura em relação a alteridade.

A entrevista não é um saber que se constitui no entrevistado e é "transmitido" para o entrevistador, mas algo que se tece conjuntamente entre ambos; trata-se de um processo que envolve interações tentativas, idas e voltas, enquadramentos mútuos que se constituem, desfazem e refazem rapidamente no tempo. Essa indefinição contínua parece ser parte do processo de entrevista quando pensado dentro de uma perspectiva da comunicação enquanto "radical indeterminação", na expressão de Ferrara (2011). A autora propõe, aliás, uma diferença entre a "comunicação", processo heurístico mais restrito, substantivo, em relação às possibilidades abertas pelo "comunicar", a ação 
que se constitui na direção do outro e, principalmente, com o outro - o "entre" da "entrevista". Holstein e Gubrium (1995, p. 57) denominam "entrevista ativa" esse direcionamento à construção mútua dos códigos relacionais da entrevista: o que "emerge" da pesquisa, em suas palavras, é reciprocamente construído nas interações dos entrevistados.

Um desafio é lidar com a subjetividade entre entrevistado e entrevistador, estabelecendo uma relação adequada, por isso a necessidade de ter os objetivos claros, saber distinguir e categorizar as contribuições do entrevistado. Segundo Szymanski (2011), é preciso considerar a construção do significado na narrativa e a presença de uma intencionalidade por parte de quem é entrevistado e por parte de quem entrevista, no jogo de emoções e sentimentos que permanecem como pano de fundo ao longo do processo.

A experiência e a memória, transformadas em discurso na fala dos entrevistados, não deixa de passar por filtros subjetivos e objetivos responsáveis por mediar a elaboração da fala na entrevista. A dimensão discursiva da entrevista, compreendida como produção textual, é levada em consideração no sentido de recordar que se tratam de dados produzidos em uma situação que poderia ser entendida artificial, no sentido original da palavra "artifício", "feita a partir da técnica", e, portanto, não "natural". A proximidade interpessoa da relação de pesquisa parece esconder uma possivel armadilha epistemoló gica no sentido de misturar a proximidade com o sujeito entrevistado com possibilidade de entendimento do fato: dito de outra maneira, a entrevista coloca a pesquisadora ou pesquisador diante de um sujeito, mas não necessariamente diante de um fato ou acontecimento em si, senão enquanto resultante dessa mediação do sujeito falante e que, portanto, precisa ser levado em consideração como uma das dimensões existentes na entrevista.

Após o período da entrevista, que, apesar do empenho do pesquisador em seguir todos os passos e procedimentos e tratar cada entrevista como única, algumas serão mais emotivas, outras mais técnicas, com mais ou meno empatia e confiança. É chegado o momento de encerrar o encontro e assim como os sinais e gestos para o início, mensagens para prolongar ou descontinuar a conversa emergirão. Assim, é possível sublinhar uma dimensão ética na entrevista não em termos procedimentais, mas como ética da alteridade, segundo Martino e Marques (2018), um dos pontos fundantes do processo comunicacional. Isso implica a responsabilidade ética da compreensão das categorias e modos de endereçamento à realidade feitos pelo entrevistado, como recordam Moré (2015) e D'Espíndula e França (2016, p. 497).

O entrelaçamento do que foi relatado nas entrevistas com os pressupostos do pesquisador, associados ao referencial teórico-bibliográfico devem tecer os resultados da pesquisa. Em ambos os casos foi necessário separar estereótipos e pré-conceitos para compor as interpretações da realidade. No caso da pesquisa em multinacionais, a tendência seria de relatar comportamentos de determinadas nacionalidades, incluindo a brasileira, numa perspectiva ne- gativa. Como o objetivo principal do estudo era compreender a comunicação intercultural entre os atores, tendo como pano de fundo as empresas, foi necessária cautela na interpretação dos relatos, sem deturpar o que fora dito, porém mantendo o sentido e intensão do entrevistado.

Repetir a mesma pergunta de formas diferentes foi uma das práticas adotada na pesquisa em educação para checar os relatos dos professores e delinear em que medida as dimensões da violência nas escolas públicas pode transformar a comunicação entre professor e aluno. Entretanto o exercício de fechamento da entrevista, com a proposta de sintetizar em uma palavra as experiências relatadas, corroborou para a verbalização "mais solta" do entrevistado sobre o tema pesquisado, dialogando de maneira ainda mais consistente com as interpretações e reflexões a respeito da realidade entre professor e aluno.

\section{Considerações finais}

Se podemos seguir a definição de Maria Isaura P. de Queiroz (1991, p. 27), a metodologia não é apenas uma descrição dos procedimentos de pesquisa, embora possa inclui-los, mas, sobretudo uma reflexão crítica sobre as práticas de investigação. Em suas palavras, trata-se de pensar a metodologia como "apreensão do sentido íntimo do que se quer efetuar, assim como das operações a serem realizadas", procurando "o desvendamento do significado profundo que existe em seus objetivos e procedimentos, inclusive na própria linguagem por ele utilizada".

A entrevista é um momento privilegiado de encontro comunicacional intersubjetivo. O nome "entrevista", observado em sua etimologia, divide-se imediatamente em o que está "entre" duas visões, o mesmo vale para o inglês "interview" e para o espanhol e italiano "entrevista", ligando-se de maneira mais oblíqua ao francês "entretien". É possível, de maneira breve, derivar algumas perspectivas da prática de entrevista trabalhando com essa origem. A validade e a confiança dos resultados de uma entrevista, indica Slembrouke (2004, p. 108), leva em conta suas dimensões linguísticas e interacionais, em um exercício de autorreflexão que não deixa de lado seus parâmetros de contribuição ao saber.

A entrevista permite a obtenção e informações "em primeira mão", a partir do depoimento de pessoas envolvidas, de maneira direta ou indireta, com ele. Ao mesmo tempo, ajuda a conhecer os estados subjetivos, a subjetivação das vivências transformadas em narrativa e discursivamente expressas pelo entrevistado. A prática comporta, nesse sentido, uma dupla dimensão: de um lado, conhecer uma situação através do olhar do entrevistado e, de outro, saber algo sobre o próprio entrevistado. Evidentemente, na prática, essas duas dimensões não podem ser separadas - o discurso sobre algo não deixa de lado suas condições efetivas de produção pelos sujeitos, mas é possível dirigir o foco dos questionamentos. 
Isso permite dimensionar esta ideia de informações "em primeira mão" operada na prática de entrevista, por isso o uso de aspas. Nesse sentido, parece ser importante ter em mente alguns limites epistemológicos da entrevista en quanto via de acesso "natural" a uma determinada situação ou acontecimento. Partindo do pressuposto de que a fala do entrevistado efetivamente "revela" o que houve, é questionável, nesse sentido, a própria possibilidade de se ter acesso a estados subjetivos do entrevistado. A entrevista, ao colocar frente a frente duas subjetividades, apresenta-se como um espaço privilegiado de encontro com o outro e, por isso, parece implicar, de saída, uma dimensão estética no sentido de elaboração de uma sensibilidade mútua que, por seu turno, coloca uma dimensão ética - a responsabilidade de se estar diante do outro, de fazer ou ouvir perguntas, de colocar a realidade dentro de uma ordem narrativo-discursiva dentro de um artifício, mas com vistas a algum tipo de entendimento ou compreensão.

\section{Referências}

ARSAND, L.: ARSAND, P. The joint production of confession in qualitative research interviews. Journal of Applied Linguistics and Professional Practice, vol. 11, no. 23, 2014, pp. 227-247. ARSEL, Z. Asking Questions with Reflexive Focus. Journal of Consumer Research, vol. 44, no. 1, 2017, pp. $939-$
948.

BAITELLO, N. A era da iconofagia: ensaios de comunicação e cultura. São Paulo: Hacker, 2005.

BARROS FILHO, C.; MARTINO, L. M. S. O habitus na Comunicação. São Paulo: Paulus, 2003.

BAUER, M W.; GASKELL, G. Pesquisa Qualitativa com Texto, Imagem e Som: um manual prático. Petrópolis: Vozes, 2008

BOURDIEU, P. Questões de Sociologia. Rio de Janeiro: Marco Zero, 1983.

BRAGA, J. L. A prática da pesquisa em Comunicação: abordagem metodológica como tomada de decisões. E-Compós, Brasilia, v.14, n. 1, jan/abr. 2011 BRAGA, J. L. Nem rara, nem ausente - tentativa. Trabalho apresentado no 20o. Encontro da Compós. Anais... Rio de
Janeiro: PUC-RJ, junho 2010.

D'ESPINDULA, T. S.; FRANÇA, B. H. S. Aspectos éticos e bioéticos na entrevista em pesquisa: impacto na subjetividade. Revista Bioética, no. 24, vol. 3, 2016, pp. 495-502.

FERRARA, L. D'A. A comunicação entre hábito e consciência. Trabalho apresentado no 210. Encontro da Compós. Anais... Juiz de Fora: UFJF, junho 2012.

FERRARA, L. D'A. A epistemologia de uma comunicação indecisa. Trabalho apresentado no 22o. Encontro da Compós Anais. Salvador: UFBA junho 2013.

FERRARA, L. D'A. Olhar Periférico. São Paulo: Edusp, 1996

RANÇA, V. Paradigmas da Comunicação: Revisitando um texto. Palestra proferida no IV Seminário Teorias da Comunicação. Anais... Belo Horizonte: UFMG, 21 a 25 de setembro, 2014.

FRASER, M. T. D.; GONDIM, S. M. G. Da fala do outro ao texto negociado: discussões sobre a entrevista na pesquisa qualitativa. Paidéia, no. 14, Vol. 28, 2004, pp. 139-152.

GOFFMAN, E. A representação do eu na vida cotidiana. São Paulo: Editora Vozes, 2014

GOFFMAN, E. Comportamentos em lugares públicos: notas sobre a organização social dos ajuntamentos. Tradução Fábio Rodrigues Ribeiro da Silva. Petrópolis, RJ: Ed. Vozes, 2010.

GOLDEMBERG, Mirian. A arte de pesquisar: como fazer pesquisa qualitativa em Ciências Sociais. $8^{\mathrm{a}}$ ed. Rio de Janeiro: Record, 2004.
LOPES, A. G. S. Processos midiáticos de comunicação e as dimensões da violência no ensino público. São Paulo: Cásper Líbero, 2019 (Texto Inédito).

HOLSTEIN, J. A.; GUBRIUM, J. F. The active interview. Londres: Sage, 1995

JENSEN, R.; CHRISTY, K. Interview and Focus Group Research: A Content Analysis of Scholarship Published in Ranked Journals. Communication Methods and Measures, no. 7, vol. 1, 2013, pp. 126-133.

KAUFMANN, J-C. L'Entretien Compréhensif. Paris: Nathan, 1996.

KIRK, J.; MILLER, M. L. Reliability and validity in qualitative research. Londres: Sage, 1986

LAZARSFELD, P. The use of detailed interview in marketing research. Journal of Marketing Research, no. 1, vol. 2 , Julho de 1937.

LAZARSFELD, P. The use of detailed interview in marketing research. Journal of Marketing Research, no. 1, vol. 2, Julho de 1937

LIMA, V. Repensando a (s) teoria (s) da comunicação. In: MELO, J. M. Teoria e pesquisa em comunicação. São Paulo: Intercom/Cortez, 1983

MANZINI, E. J. Uso da entrevista em dissertações e teses produzidas em um programa de pós-graduação em educação. Revista Percurso. Maringá, v. 4, n. 2, p. 149-171, 2012.

MARCONDES FILHO, C. A Comunicação no sentido estrito e o Metáporo. Trabalho apresentado no 210. Encontro da Compós. Anais... Juiz de Fora: UFJF, junho 2012.

MARIANO, A. F. C. A entrevista como tema de pesquisa no campo da comunicação. Famecos, v. 25, n. 2, p. 1-17, maio-ago. 2018, pp. 1-17.

MARQUES, Â. C. S. e MARTINO, L. M. S. "Não fale com estranhos": Solidariedade e Comunicação. Porto Alegre: Revista Famecos v. 24 n. 2, 2017

MARQUES, Â. C. S. e MARTINO, L. M. S. A afetividade do conhecimento na epistemologia: a subjetividade das escolhas na pesquisa em Comunicação. São Paulo: Revista Matrizes v. 12 n. 2, 2018

MARTINO, L. M. S. Métodos de Pesquisa em Comunicação. Petrópolis: Vozes, 2018.

MARTINO, L. M. S. Dimensões e limites da empatia na Comunicação: explorações na trilha de Husserl e Stein. Trabalho apresentado no 28॰ Encontro da Compós. Anais... Porto Alegre: UFRGS, junho de 2019.

MORÉ, C. L. O. O. A "entrevista em profundidade" ou "semiestruturada" no contexto da saúde. Investigação Qualitativa em Ciências Sociais - Atas do CIAIQ 2015, Vol. 3, pp.126-13.

POTTER, A. Managing productive academia/industry relations: the interview as research method. Media Practice and Education, 2018, VOL. 19, NO. 2, 159-172.

SOUZA, V. P. Identidades plurais, visão singular: a articulação da comunicação em organizações no contexto global. São Paulo: Cásper Líbero, 2019 (Dissertação de Mestrado).

QUEIROZ, M. I. P. Variações sobre a técnica de gravador no registro da informação viva. São Paulo: T. A. Queiroz, 1991

Rizo, M., Romeu, V. Cultura y comunicacion intercultural. Aproximaciones conceptuales. E-Compós. V.6. (2006). Disponivel em: https://doi.org/10.30962/ec.v6io.85. Acesso em novembro de 2018.

SANTAELLA, L. Comunicação e pesquisa: projetos para mestrado e doutorado. São Paulo: Hacker Editores, 2001.

SCHEIN, E. Organizational culture and leadership. São Francisco, EUA: Editora Jossey-Bass, 2004

SLEMBROUKE, S. Reflexivity and the research interview. Critical Discourse Studies. Vol. 1, No. 1 April 2004, pp. 91-112.

SZYMANSKI, H. A entrevista na educação: a prática reflexiva. Braślila: Liber Livro Editora, 2004.

TEDESCO, S. H.; SADE, C.; CALIMAN, L. V. A entrevista na pesquisa cartográfica: a experiência do dizer. Fractal, no. 2, vol. 25, Maio-Agosto 2013, pp. 299-322.

WILLIAMS, R. Keywords. Londres: Fontana, 2003. 